\title{
Water Saving Retrofit Device for Squatting Pan Without Trap
}

\author{
Fangqing $\mathrm{Yi}^{1, *}$, Danyang $\mathrm{Li}^{2}$ \\ 130 Xueyuan Road, Haidian District, Beijing, China \\ ${ }^{2} 30$ Xueyuan Road, Haidian District, Beijing, China
}

\begin{abstract}
Under the wave of the "toilet revolution" and toilet technology innovation, we started with squatting pan without trap and aimed to achieve the goal of technological innovation and saving water resources by installing water-saving devices on the existing squatting pans. The water-saving reforming device for squatting pans has a simple structure and is easy to install. And the materials used have advanced scientific features. The device can solve the problems of over much water consumption and uncleanness of existing squatting pans. This water-saving device has strong economic value and outstanding environmental performance. Compared with other water-saving solutions, this design takes into account the demands of the entire chain of stakeholders in production, installation and use. Therefore, it can be easily applied and popularized.
\end{abstract}

\section{Significance of research}

China is a country with severe water shortage. At present, the annual consumption of tap water accounts for about $30 \%$ of the total annual water shortage in China.At present, the squatting pan without trap widely used in China has problems such as large water consumption and repeated flushing when removing excrement, thereby causing waste of water resources. Therefore, it is urgent to find a water saving reforming device that can be quickly promoted.Although some experts and scholars have proposed theoretically feasible solutions, the main reason why their relevant researches are difficult to put into production is that the cost of the original squatting pantry is too high, and the qualifications of the production enterprises are high.Therefore, the simple modification of the currently widely used squatting pan without trap can be the most direct and effective way to solve the problem.

In order to minimize the resistance in promoting the use of water-saving devices, our retrofit device is designed to meet the needs of the entire chain of stakeholders in production, installation and use.From the aspects of material selection, installation, water saving, and user habits, we not only propose a scientific and feasible water-saving scheme in theory, but also carry out practical design, and strive to transform the results into applications more quickly.

\section{Problem definition and analysis}

\subsection{Problems with squatting pan without trap}

Due to the flexibility of the water, the water will be deformed when it comes into contact with the excrement and will be automatically diverted. In this way, the kinetic energy of the water is not fully utilized, and the existing squatting pan often takes repeated flushing to completely wash away the excrement.

Traditional squatting pans also have problems such as excessive water output and easy outward spraying. When flushing, the water will splash out of the squatting pan because the momentum is large and the kinetic energy of the water is not fully utilized. In addition, when the amount of water is large, the water will spread out of the groove, and the excrement may dissolve in the water, which will cause great trouble for cleaning.

\subsection{Defects of existing research}

\subsubsection{Uneconomical and large transformation.}

Some existing water-saving squatting pans are designed to be very different from traditional squatting pans, and even require major structural changes to the sewage pipes of the original building. For example, Zhejiang University's flip-type "waterless" squatting pan[1], by turning the urinal, uses the gravity of the dirt to make the dirt into the pipe. However, such a design will make the design and material selection of the sewage pipe of the building more complicated. If the squatting device is to be used, the original squatting device will be removed, which is uneconomical.

\subsubsection{Not clean, the scope of application is small.}

There are some new squatting pans that can only be used in certain environments. Han Bin[2] proposed a new type of pedal-type squatting pan, which can be automatically opened when the person steps on the

\footnotetext{
*Fangqing Yi: yifangqingi@163.com
} 
squatting pedal, and automatically closes when the person leaves, separating the septic tank from the toilet interior. Obviously, it can only serve the rural areas that lack water supply and drainage systems and the field oil and geological exploration mobile camping services that require mobile operations. And the residue of the excrement still adheres to the cover of the drain, which is not clean.

\subsection{Key to solving problems}

Based on the above analysis, it can be found that the key to solving the water saving problem of the squatting pan without trap is as follows:

First,the cost of the design should be reasonably controlled, and the modification of structures other than the squatting (pipe structure, etc.) should be avoided as much as possible. It is best to renovate on the basis of the original squatting pan to avoid uneconomical changes to the original squatting pan.

Second,the technical implementation of the design should not be too complicated. Otherwise, our design may have problems that cannot be promoted on a large scale.And the user's habits should be considered when designing the solution, allowing the user to accept and have a comfortable product experience.

\section{Overall description of the device}

\subsection{Device composition}

As shown in Fig.1, the blue part is a plate brush skeleton, made of ABS material, with a curved front surface and a concave surface on the back surface to maximize the power of water that is flushed from the front wall surface of the squatting pan. The surface of the plate brush and the portion in contact with the surface of the squatting pan are covered with nylon fibers. The carbon rod is mounted on the wall below the two pedals of the squatting pan through the support, and the slab skeleton is connected to the plastic linear bearing by bolts and slides on the carbon rod through the linear bearing. The back of the brush is connected to the inner wall of the front end of the squatting pan by a stainless steel spring (indicated by a white plate in the figure).

The plate brush slides on the carbon rod through the linear bearing, and the linear bearing is in close contact with the carbon rod, so that almost no foreign matter can be stuck in. At the same time, the structure of the linear bearing also allows tiny foreign matter to enter and be discharged from the side. Although the two are in close contact, the carbon rod has a very small coefficient of friction, so it can slide freely, and the device will not be stuck if it is used for a long time.Stainless steel springs, hydrophobic carbon rods and linear bearings are used in the unit, so there is no effect on water immersion.

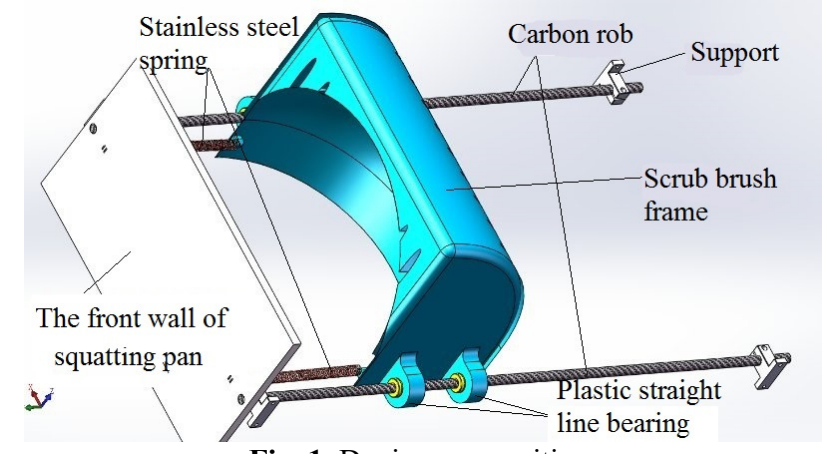

Fig. 1. Device composition.

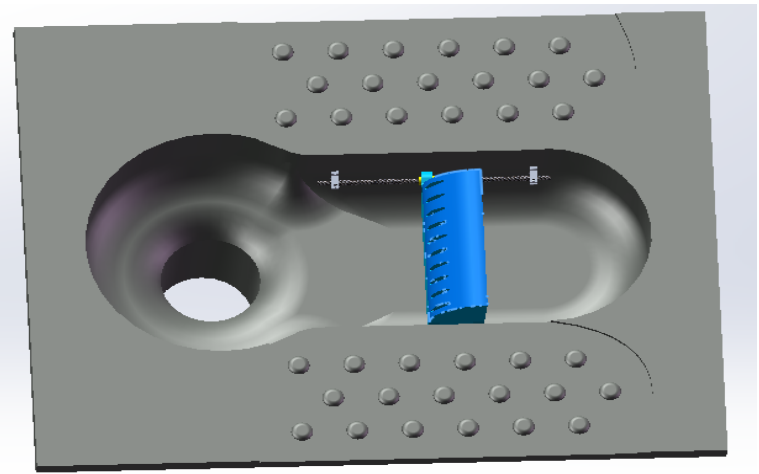

Fig. 2. Installation status.

\subsection{Feasibility analysis of key materials}

Since the surface of the brush is in contact with the surface of the squatting pan for a long time, the material itself and its influence on the surface of the squatting pan should be considered when selecting the material. The material of the nylon fiber is finally selected according to special requirements.

Respecting squatting pan without trap, the nylon fiber does not hurt the glaze: Most of the squatting pans used today are ceramics, and the glaze is more delicate. Nylon fiber is soft in texture and its abrasion resistance is the best among all textile fibers. Under the same conditions, its abrasion resistance is 10 times that of cotton. In addition, nylon fibers also have good elasticity and high elastic recovery. With an elongation of $10 \%$, its elastic recovery rate is $99 \%$, which ensures that the glaze of the squatting pan will not be damaged during use.

Antibacterial and deodorant: Since the material is in contact with excrement and is exposed to the air for a long time, it needs to have certain antibacterial property and should not emit odor to affect the environment. The selected nylon fiber contains a special ceramic material, and the released silver ions can achieve good antibacterial effect and deodorant effect. Due to the elasticity of the material, it can be attached to the surface of the squatting pan to avoid the leakage of excrement when flushing.

\subsection{Working process}

Initially the spring remains the original length and the brush rests at the front end of the squatting pan (the 
opposite end of the sewer hole). When the device is installed, the water outlets on both sides are blocked, leaving only the front main water outlet.

After the user slams the flush switch as usual, the water is ejected from the front end, pushing the plate brush forward from the concave surface behind the plate brush against the spring resistance.After the plate brush pushes the excrement of different characteristics into the hole, part of the water of the plate brush surface flows away from both sides of the plate brush, and a part of the water overflows from the upper part of the plate brush to the side of the plate brush and the excrement contact, to clean up very little residue on the plate brush. At the same time, after the thrust of the water received by the brush disappears, the plate brush slides back to the original position under the action of the spring force to end the work. Fig.3 is the diagram of some working processes (the spring is not included in the figure)

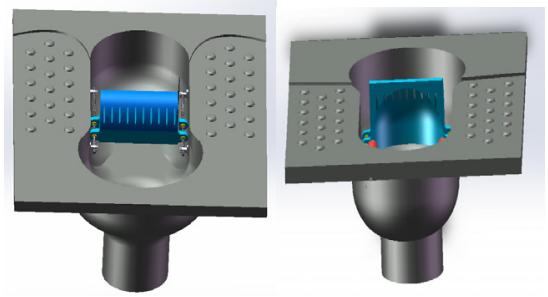

Fig. 3. Working process.

\section{Feasibility analysis of the design}

\subsection{Technical feasibility analysis}

Our equipment is not difficult to achieve in terms of material selection, plant complexity and technical difficulty. This is also the advantage of this solution. The key is to prove that our device can use water thrust to completely clean the excrement. Since the two sides of the plate brush are not in contact with the wall surface, only the nylon fiber is in contact with the bottom surface of the squatting pan, so that the weight of the plate brush is almost entirely borne by the carbon rod. Therefore, the pushing device is subjected to four forces: the friction between the linear bearing and the carbon rod, the friction between the nylon fiber and the bottom surface of the squatting pan, the friction between the excrement and the wall surface, and the spring force of the spring. The detailed calculation process is below. Let's do a qualitative analysis below:

The compression deformation of the nylon fibers at the bottom of the brush produces an elastic force against the plate brush and against the bottom surface of the squat. The upward elastic force overcomes the brush gravity and reduces the friction between the carbon rod and the linear bearing; the downward elastic force increases the friction between the nylon fiber and the bottom surface of the squatting pan, and the effects of the two forces on the pushing device cancel each other out. For the friction between the carbon rod and the linear bearing, due to the extremely low friction coefficient of the carbon rod and the hydrophobic nature, the friction between the bearing and the bearing is extremely small, which is small relative to the spring force of the spring and can be neglected.

At the same time, in the course of the work of the existing squatting pan, the three sides flushing will cause part of the thrust to cancel each other. Therefore, our solution cuts off the water outlets on both sides of the squatting pan, and sets the amount of water at the main water outlet of the front end of the squatting pan according to the energy required to push the squeegee and excrement, so that significantly reduced previous collision losses. Moreover, the back surface of the brush is spherical, which better encapsulates the sprayed water and more fully utilizes the kinetic energy of the water. Moreover, under the condition that the flushing amount is less than $6 \mathrm{~L}$ (compared by the common squatting pans sold in the market and the industry data, the average flushing needs 6L water), it can not only promote the plate brush to clean the excrement in one time, but also reduce the waste in the second flushing.

For device replacement and life:First, The material of each component is selected according to the characteristic of the use process. The life of the material itself is long, and the wear during use have no significant influence on the device function.Second, the components of the device are low in cost and simple in assembly principle, and are easy to disassemble, so that only the damaged components need to be replaced when the device fails. It will not cause waste of materials, but also ensure the simplicity and low cost of maintenance.Third,the total cost of the device is low, and the cost of replacing the device as a whole is acceptable.

\subsection{Environmental feasibility analysis}

We mainly calculate the water demand of a single flush to push the brush and excrement, and discuss the environmental feasibility of the device from the aspect of water saving.

According to the relevant industry product information and calculation practices, the data required for water saving calculation are as follows: the main outlet diameter of the squatting pan is $d=50 \sim 55 \mathrm{~mm}$, and $\mathrm{d}=52 \mathrm{~mm}$ is taken in the calculation. The pressure $\mathrm{P}$ of the water at the water outlet is in the range of 0.1--0.6 $\mathrm{Mpa}$, and the water-discharging speed V1 is $1-1-3 \mathrm{~m} / \mathrm{sec}$, and the general engineering calculation usually takes 1.5 $\mathrm{m} / \mathrm{sec}$.

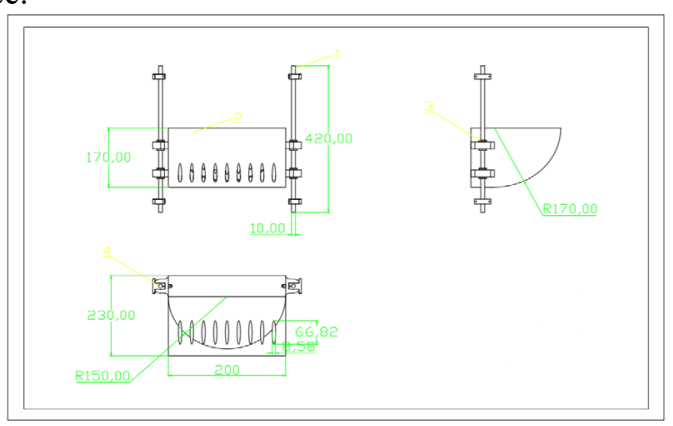

Fig. 3. Size chart

Assume that the red dotted line is the water flow ejected from the main outlet at the front end of the squatting pan when flushing. The water flow is affected 
by the surface force $\mathrm{R}$ of the plate brush, the direction is directed to the water outlet and perpendicular to the plate brush.

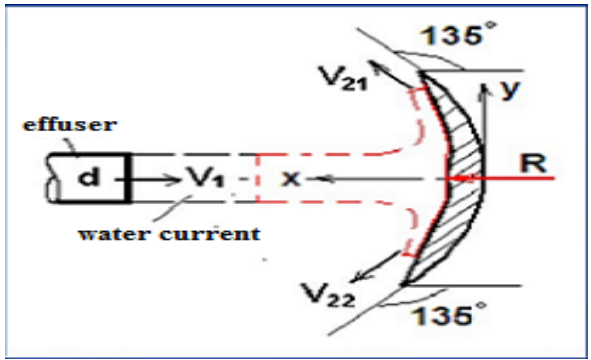

Fig. 4. Force structure.

The water flow is exposed to the atmosphere after being sprayed from the nozzle, and the surface pressure is 0 , so the surface forces $F 1=0$ and $F 2=0$ at the inlet and outlet ends. Lebernoulli equation:

$$
Z_{1}+\frac{P_{1}}{\gamma}+\frac{V_{1}^{2}}{2 \mathrm{~g}}=Z_{21}+\frac{P_{21}}{\gamma}+\frac{V_{21}^{2}}{2 \mathrm{~g}}
$$

Since the water flow is all exposed to the atmosphere,so $P_{1}=0, \quad P_{21}=0, \quad$ the mass force is ignored in the momentum theorem, $V_{21}=V_{1}$, $\mathrm{V}_{22}=\mathrm{V}_{1}$.

Since the plate brush is symmetrical up and down, the flow rate of the upper and lower flows is equal when neglecting other irrelevant factors such as gravity.

$$
\begin{aligned}
& Q_{1}=\frac{\pi}{4} d^{2} V_{1} \\
& F_{\text {out }}+F_{\text {in }}+R=\rho Q V_{\text {out }}-\rho Q V_{\text {in }} \\
& R=\rho Q_{21} \cdot V_{21} \cdot \cos 45^{\circ}+\rho Q_{22} \cdot V_{22} \cdot \cos 45^{\circ}-\rho Q_{1}\left(-V_{1}\right)
\end{aligned}
$$

$$
\text { (4) }
$$

Find $Q_{1}=3.186 \mathrm{~L} / \mathrm{s}, \mathrm{R} \approx 8.158 \mathrm{~N}$. According to the data of the manufacturing enterprise, the amount of water in a single flush should produce $8 \sim 10 \mathrm{~N}$ force to the excrement, so it can be concluded that the resistance from the excrement received by the brush is about $10 \mathrm{~N}$. At the same time, a stainless steel spring with a spring coefficient of $40 \mathrm{~N} / \mathrm{m}$ was selected, and the length was $400 \mathrm{~mm}$ and the elastic force was $12 \mathrm{~N}$ when it was extended above the sewer hole. In order to overcome the resistance of excrement and spring, the water requirement is about $3.186 \mathrm{~L}$.

Considering the existence of a small friction between the carbon rod and the bearing, the actual water demand is slightly larger than $3.186 \mathrm{~L}$, and the water demand can be expanded to $3.5 \mathrm{~L} \sim 3.8 \mathrm{~L}$. According to product data on the market, the average flush requires $6 \mathrm{~L}$ of water. Therefore, the initial estimate of the device can save about $2.2 \mathrm{~L} \sim 2.5 \mathrm{~L}$ of water.

\subsection{Economic feasibility analysis}

The average industry profit rate of China's manufacturing industry is around $10 \%$. Since the price of each component of the obtained device is the online retail price, the price is higher than our wholesale price, and the impact of the income tax on the profit rate needs not to be considered in our calculation. Take $30 \%$ as the rate of return to estimate the cost price. The calculation formula is:

Estimated cost price $=$ Market retail price $/(1+30 \%)$

After analyzing the size and usage of the components of the device, combined with the online retail price of each component, the basic cost of the unit is obtained, as shown in the following table:

Table 1. Basic cost of unit installation.

\begin{tabular}{|l|l|l|l|l|l|}
\hline Project & Specification & \multicolumn{2}{|c|}{$\begin{array}{c}\text { Market retail } \\
\text { price }\end{array}$} & \multicolumn{2}{|c|}{$\begin{array}{c}\text { Estimate cost } \\
\text { price }\end{array}$} \\
\hline Nylon fabric & $918.62 \mathrm{~cm}^{2}$ & 4.50 & yuan & 3.46 & yuan \\
\hline $\begin{array}{l}\text { Solid carbon } \\
\text { rod }\end{array}$ & $\begin{array}{l}\text { DIA } 10 \mathrm{~mm} \\
\text { length } 140 \mathrm{~cm}\end{array}$ & 52.00 & yuan & 40.00 & yuan \\
\hline $\begin{array}{l}\text { Screw nuts and } \\
\text { springs }\end{array}$ & & 6.50 & yuan & 5.00 & yuan \\
\hline ABS materials & $\begin{array}{l}\text { Thickness } 2 \mathrm{~mm} \\
600 * 800 \mathrm{~mm}\end{array}$ & 50.20 & yuan & 38.62 & yuan \\
\hline $\begin{array}{l}\text { Installation and } \\
\text { processing cost }\end{array}$ & & 20.00 & yuan & 15.38 & yuan \\
\hline Total & & 133.20 & yuan & 102.46 & yuan \\
\hline
\end{tabular}

The results show that the total cost of a water-saving retrofit device for a squatting pan is about 102.46 yuan. With the continuous promotion of this device, the cost will be further reduced due to optimization of production lines and economies of scale. In addition, it is easy to install without changing the original squatting pan, which will save a lot of manpower and material resources and has strong economic feasibility.

\section{Future research direction}

In the future improvement, we will mainly modify the existing equipment from the structural design of the device or the physical structure or principle of the water spray device, and carry out innovation and improvement under the premise of maintaining the advantages of the original design.

Our design still needs to be driven by manpower. If automated, we can provide users with a more comfortable and convenient product experience, and reduce the extra waste caused by the unmanned management of the washing device. Automating not only enhances our water-saving features, but also enhances user comfort, which is one of our future improvements. We will consider incorporating existing infrared sensing technology, microcomputer programming technology, etc. into our design.

\section{Research conclusions and values}

\subsection{Contribution to the environment}

At present, tap water is widely used in major cities in China. The annual consumption of tap water in flushing accounts for about $30 \%$ of the total water shortage in 
China. With the popularization of health education and the development of the national economy, the number of flushing squatting pans in public toilets and other places in China has gradually increased. Therefore, the application of water-saving reforming devices has a strong practical significance.

According to the "Statistical Communique of the People's Republic of China on National Economic and Social Development 2016" promulgated by the National Bureau of Statistics on February 28, 2017, at the end of 2016, the total population of the mainland China was 138.271 million, of which the urban resident population was 792.98 million and the rural registered population was 58.973 million.

The unit's water saving capacity is $2.2 \mathrm{~L} \sim 2.5 \mathrm{~L}$, and $2.2 \mathrm{~L}$ is taken here. Assume that the proportion of undisturbed squatting pans in urban and rural permanent residents is $20 \%$ and $15 \%$ respectively, and the average number of uses per person per day is 5 times. The results are as follows:

Table 2. Water saving statistics(day).

\begin{tabular}{|l|c|c|c|c|}
\hline & $\begin{array}{c}\text { Population/ten } \\
\text { thousand }\end{array}$ & $\begin{array}{c}\text { Ratio of } \\
\text { users }\end{array}$ & $\begin{array}{c}\text { Number of } \\
\text { users/ten thousand }\end{array}$ & $\begin{array}{c}\text { Water } \\
\text { savings/day }\end{array}$ \\
\hline Urban & 79298 & $20 \%$ & 15859.60 & $174455.6^{*} 10^{4} \mathrm{~L}$ \\
\hline Rural & 58973 & $15 \%$ & 8845.95 & $97305.45^{*} 10^{4} \mathrm{~L}$ \\
\hline Total & 138271 & & 24705.55 & $\begin{array}{c}271761.05^{*} 10^{4} \\
\mathrm{~L}\end{array}$ \\
\hline
\end{tabular}

It is estimated that the water-saving retrofit device can save water $271761.05 \times 10^{4} L$, about 2.72 million tons of water per day.

\subsection{Contribution to stakeholders}

\subsubsection{For manufacturing companies}

The device has simple production process and low qualification requirements for enterprises, and can carry out large-scale production in a short period of time and bring profits to enterprises.

Due to the innovation of this water-saving retrofit device, it will help the company to optimize the production line and further improve the product in the production process, thus forming a new profit model and enhancing the innovation and competitiveness of the enterprise.With the wide application of the water-saving retrofit device for the squatting pan without trap, the production of the enterprise is easy to form a scale effect, which is beneficial to the technical improvement of the enterprise and further reduce the cost.

\subsubsection{For users}

There is no change in the operating method after the installation of the water-saving retrofit device. The method of use is simple, hygienic and labor-saving, and the user is psychologically acceptable.

\subsubsection{For the installation site}

The installation site of the water-saving reconstruction device is mainly public places such as campus, office building, tourist attractions and traffic stations.

Low cost: The installation of the water-saving retrofit device does not require major renovation of the original squatting structure, which will greatly reduce the time and resource cost of the installation site.

Low labor: The water-saving retrofit device is simple in structure, easy to clean, low in technical requirements, and simple in maintenance. Therefore, the relevant staff do not need additional training or increase the workload. The application of the water-saving retrofit device will greatly reduce the residue of the excrement, and thus will reduce the workload of the toilet cleaning personnel.

Green development: The main purpose of the application of this device is to save water resources. The installation site can not only save water cost, but also reflect the green sustainable development concept of saving resources and protecting the environment, which will help the installation site to fulfill social responsibility and establish a good public image.

\section{References}

1. Zhejiang University: flip-type "waterless" squatting pan [J]. China Electric Power Education, 08 (2017).

2. Han Bin, Li Ying. Development of a new type of pedal squatting device [J]. Machinery, 06 (2006).

3. Cheng Wei, Wang Shaoping. A new type of watersaving intelligent toilet design [J]. Development and innovation of mechanical and electrical products, $\mathbf{0 1}$, 30 (2017).

4. Liu Renxian. From the perspective of fluid mechanics, water-saving flushing device[J]. China Ceramic Industry, 05(2005): 28-30.

5. $\mathrm{Xu}$ Weiguang. Research on Funnel-type Squatting Pan [J]. Ceramics, 05 (1993): 43-45.

6. Liang Wenwei, Huang Jianbing. Reforming the squatting device to save energy and improve economic benefits [J]. Ceramics, 06 (1992): 40-41.

7. Zhao Weiming. Improving the connection process between the squatting pan and the washing pipe[J]. Harting Technology Newsletter, 03(1992): 29-28.

8. Ning Junyang. Research on improving the scouring performance of squatting pan $[\mathrm{J}]$. Ceramics, 06 (1983): 40-41.

9. Huang Shengzhen's technical problems and measures to be solved to promote the toilet revolution [J] China Environmental Management, 02, 10 (2018): 49-52.

10. Dai Bin. The era significance and promotion strategy of the toilet revolution [N]. China Travel News, 007 (2015). 